\title{
Los indigenismos léxicos en la Relación de la jornada de Cíbola: la americanización del español*
}

\author{
Indigenous loanwords in the Relación de la jornada de Cíbola: \\ the Americanization of the Spanish language
}

\author{
Patricia Giménez-Eguíbar \\ Western Oregon University / IEMYRhd (Spain) \\ gimenezp@mail.wou.edu \\ ORCID iD: https://orcid.org/0000-0002-1871-2239 \\ Sonia Kania \\ University of Texas at Arlington \\ skania@uta.edu \\ ORCID iD: https://orcid.org/0000-0001-6339-6581
}

RESUMEN: El artículo ofrece un análisis filológico-lingüístico de la Relación de la jornada de Cíbola de Pedro de Castañeda de Nájera, texto que narra la expedición de Francisco Vázquez de Coronado de 1540-1542. El estudio se centra en los préstamos léxicos indígenas en el texto junto con su documentación tanto en otros textos coloniales como en obras lexicográficas. Al igual que las modificaciones semánticas del vocabulario patrimonial, los indigenismos representan la indianización de la lengua española, esto es, su adaptación al medioambiente americano.

Palabras clave: indigenismo, tainismo, nahuatlismo, codificación, americanismo, americanización.

ABSTRACT: The article presents a philological-linguistic analysis of the Relación de la jornada de Cíbola by Pedro de Castañeda de Nájera, a text that narrates the 1540-1542 expedition of Francisco Vázquez de Coronado. The study focuses on the indigenous loanwords in the text, together with their documentation in other colonial texts, as well as in lexicographic works. Indigenous borrowings, like semantic extensions of patrimonial Spanish words, represent the Indianization of the Spanish language, in other words, its adaptation to the American context.

\footnotetext{
* Agradecemos la ayuda de las profesoras María Nieves Sánchez González de Herrero, Pilar Carrasco, Eva Bravo-García y Concepción Company Company en la elaboración de este trabajo. 
Keywords: indigenous loanword, Taino borrowing, Nahuatl borrowing, codification, Americanism, Americanization.

\section{INTRODUCCIÓN}

En este trabajo se presentan los resultados del estudio filológico-lingüístico de la Relación de la jornada de Cíbola ${ }^{1}$, texto narrativo del siglo XVI que describe la expedición de Francisco Vázquez de Coronado de 1540-1542. Pedro de Castañeda de Nájera, autor de este texto, aporta la relación testimonial más detallada de la expedición en la que participa. En este artículo nos centramos en el uso de los préstamos indígenas que se utilizan para referirse al nuevo contexto americano, mostrando así la "indianización" de la lengua (cfr. Parodi, 2006). Antes de embarcarnos en el estudio léxico, conviene contextualizarlo con un breve repaso de los eventos históricos asociados con la Relación, una descripción del texto y un resumen de sus principales características lingüísticas ${ }^{2}$.

\subsection{Trasfondo histórico}

Francisco Vázquez de Coronado llegó a Nueva España en 1535 con el primer virrey de la colonia, Antonio de Mendoza, que en 1538 nombró a Coronado gobernador de Nueva Galicia, territorio administrativo del noroeste de Nueva España ${ }^{3}$. Durante esa época circulaban muchas leyendas sobre las Siete Ciudades, una provincia mítica de riquezas innumerables cuyo lugar exacto se desconocía. En 1536, Álvar Núñez Cabeza de Vaca, superviviente de la malograda expedición de Pánfilo de Narváez, llegó a San Miguel de Culiacán después de haber recorrido a pie durante ocho años parte de los vastos territorios del norte de México. Los informes sobre su odisea parecían corroborar ciertos rumores sobre la ubicación de las Siete Ciudades, precisamente en estas tierras norteñas, además de sugerir la existencia de enormes riquezas más allá de lo explorado. Inspirado por las narraciones de Cabeza de Vaca, Mendoza envía en 1539 a fray Marcos de Niza en una primera misión de reconocimiento, cuyo guía, un esclavo negro conocido como Estebanico, había acompañado con anterioridad a Cabeza de Vaca. Mendoza pretendía la corroboración de los informes antes de comprometerse a lanzar una expedición. Al volver

\footnotetext{
1 Para la tipología textual de la relación de Indias, véase Bravo-García y Cáceres-Lorenzo (2014: 91).

2 Información basada en el esquema de Kania, Kauffeld y Sanz-Sánchez (2017). La parte histórica se basa principalmente en Weber (1992: 14-49) y Flint (2008). Otras fuentes se citan debidamente.

${ }^{3}$ El territorio equivalía en líneas generales a los actuales estados de Aguascalientes, Colima, Jalisco, Nayarit, partes de Durango, San Luis Potosí y Sinaloa.
} 
de su viaje, Niza afirma haber descubierto la gran ciudad de Cíbola y las aledañas ciudades, inspirando de este modo el mito de las Siete Ciudades de Cíbola ${ }^{4}$.

Una vez sopesadas las posibles ganancias materiales en las tierras norteñas, Mendoza encarga una expedición formal con Coronado a la cabeza, formada por un centenar de españoles, cinco frailes franciscanos (incluido Niza), dos mil aliados indígenas junto con miles de caballos y animales de carga. Coronado parte de Compostela, la capital de Nueva Galicia de aquel entonces, en febrero de 1540. Castañeda, nuestro autor, se une a la expedición en Guadalajara y viaja con el contingente principal. Dado que el riojano no forma parte de la vanguardia, ni de las misiones de exploración, parece difícil que fuera testigo ocular de todos los eventos incluidos en su narración (Flint y Flint, 2005: 378).

En julio de 1540 la vanguardia de la expedición llega a la zona de Cíbola, muy probablemente al pueblo zuni de Hawikku, al occidente del estado actual de Nuevo México5 ${ }^{5}$. Allí la expedición afronta su primera decepción: en lugar de ciudades doradas colmadas de fabulosas riquezas, se topan con los humildes asentamientos de los indios pueblo. No obstante, Coronado establece allí su cuartel para pasar el invierno, concretamente en Tiguex, al este de Hawikku en el seno del territorio pueblo en las riberas del río Grande, aproximadamente en lo que es hoy la ciudad de Albuquerque ${ }^{6}$. Desde allí se emprenden varios viajes de exploración, el más importante el de Quivira — otra tierra mítica de cuya existencia Coronado supo por el indio conocido como El Turco-, quien convence a los españoles de las riquezas, recursos y avances de las civilizaciones que habitan estas tierras. Coronado y compañía salen hacia Quivira en la primavera de 1541 .

Recorridos más de mil kilómetros por una ruta tortuosa hacen frente a su segunda gran decepción: Quivira, en el actual estado de Kansas, no solo carecía de metales preciosos sino que los asentamientos de los wichita estaban incluso menos desarrollados que los de los pueblo. En lugar de descubrir las riquezas anheladas, descubren tanto el engaño del Turco como sus verdaderas intenciones: una trampa para dejar a los españoles morir de inanición. Desilusionados, los españoles vuelven a Tiguex y Coronado, a la primavera siguiente, decide volver a Nueva Galicia, hecho no ausente de controversia según nuestro autor. Castañeda no termina el viaje de vuelta, sino que permanece en San Miguel de Culiacán, donde escribe su Relación

4 La palabra Cíbola proviene del zuni šiwin'a, una designación originalmente utilizada para referirse a sus pueblos. Se cree que a la llegada de Coronado había seis pueblos zuni, no siete. Posteriormente Cíbola designa toda la región de Arizona y Nuevo México (Craddock, 1999: 106107; Craddock y Polt, 1999: 26).

${ }^{5}$ Los zuni son una de las tribus pueblo; los pueblo reciben este nombre por vivir en comunidades o pueblos. Habitan en casas de adobe, piedra y madera con techos planos, que pueden tener varios pisos o niveles, como las de los zuni o ser viviendas de una sola altura. Véase el mapa de la zona zuni en Flint (2008: 253); cfr. Kessell (2002: 38).

${ }^{6}$ En esta provincia vivían los tiwa del sur, otra tribu pueblo. Véanse los mapas de Tiguex en Flint (2008: 254-255); cfr. Kessell (2002: 38). 
unos veinte años más tarde y donde, aparentemente, permanece hasta su muerte. La narración de Castañeda queda como testimonio que mantiene el recuerdo de Cíbola y de Quivira en la imaginación política de los españoles.

\section{DESCRIPCIÓN DEL TEXTO}

El manuscrito que contiene la Relación de la jornada de Cíbola se conserva en una copia de 1596 en la Biblioteca Pública de Nueva York (NYPL, en sus siglas en inglés) y forma parte de la colección Obadiah Rich (MssCol 2570, n. ${ }^{\text {o }}$ 63). El texto ha sido objeto de varios estudios por parte de los historiadores del suroeste de los Estados Unidos desde finales del siglo XIX, v. gr. la transcripción y traducción parcial de Winship (1896), la traducción de Hammond y Rey (1940) y la transcripción de Flint y Flint (2005). De Mora (1992), basándose en la transcripción previa de Winship, publica una edición en español y reproduce algunos errores de lectura. La edición paleográfica se llevó a cabo hace algunos años de la mano de Kania, Kauffeld y Sanz-Sánchez (2017) ${ }^{7}$. A pesar del interés que ha provocado la Relación entre estos investigadores, sigue siendo un texto cronístico relativamente poco conocido entre los estudiosos.

La narración de la Relación se dirige a un "muy magnifico señor", que suponemos se refiere a Antonio de Zorita, un destacado miembro de la Real Audiencia de México, ya que sabemos que entre 1550 y 1560 este recopila información sobre las tierras norteñas con la idea de organizar otra expedición (véase Flint y Flint, 2005: 378-383). El manuscrito de la NYPL es la única copia que se conoce. Se produjo en Sevilla, presuntamente para una edición impresa. El manuscrito consta de 157 folios y se divide en cuatro segmentos: un proemio (fols. 1r-6v) seguido de tres partes: la primera parte (fols. 7r-94v), que contiene veintidós capítulos, la segunda (fols. 95r-125r), con ocho capítulos, y la tercera y última (fols. $125 \mathrm{v}$ 157r), que está formada por nueve.

En el proemio, Castañeda justifica la decisión de escribir la relación: arrojar luz sobre la expedición y aclarar las habladurías que circulan en la época. La estructura del resto de la obra, en palabras del autor, es la siguiente:

Esta pequeña obra, la qual ba en tres partes rrepartida para que mejor se de a entender, la primera sera dar noticia del descubrimiento y el armada o campo que hi[ç]o con toda la jornada con los capitanes que alla fueron. La segunda, los pueblos y prouinçias que se hallaron y en que rrumbos y que rritos y costumbres, los animales, fructas y yerbas y en que partes de la tierra. La terçera la buelta que el campo hiço y las ocaciones que vbo para se despoblar, aunque no licitas, por

7 Los datos manejados en este trabajo están basados en esta edición electrónica, que ofrece una representación paleográfica del texto. El texto, los índices y las concordancias se encuentran disponibles en línea en Kania y Gago Jover (2018-). 
ser el mejor paraje que ay para se descubrir el meollo de la tierra que ay en estas partes de poniente, como se uera y despues aca se tiene entendido. Y en lo ultimo se tratara de algunas cosas admirables que se bieron... [fols. $3 \mathrm{v}-4 \mathrm{r}]^{8}$.

Según la cita, la narración de la expedición se centra en la primera y tercera partes, mientras que la segunda se reserva a la descripción de los pueblos y de los recursos naturales encontrados, apartado que por temática es idóneo para nuestro estudio léxico ya que relata hechos del contacto lingüístico y cultural.

En cuanto a los segmentos narrativos, también fructíferos como fuentes primarias de contacto, la primera parte detalla los preparativos de la expedición así como los eventos hasta el verano de 1541, cuando Coronado y su compañía vuelven de la exploración a Quivira; además, incluye los acontecimientos asociados con la trayectoria de la retaguardia, donde viaja Castañeda, hasta el encuentro con Coronado en Cíbola. En esta parte se describen las exploraciones a los pueblos de los hopi ${ }^{9}$ y a la Barranca Grande (ambos en el actual estado de Arizona) y a los llanos de Cíbola, hábitat de los bisontes (en los actuales estados de Nuevo México y Texas). La tercera parte narra los eventos asociados con la decisión de Coronado de volver a Nueva España: el retorno de la vanguardia a Tiguex después del viaje a Quivira y la marcha a Nueva España por Culiacán y Compostela, concluyendo con la llegada de Coronado a la Ciudad de México para informar a Mendoza. Antes de finalizar su narración, Castañeda menciona "algunas cosas admirables" (fol. 149v) que se descubren en la jornada y propone una nueva ruta para volver a las tierras de Cíbola en el futuro.

\section{CARACTERÍSTICAS LINGÜÍSTICAS}

En este apartado se describen los principales rasgos lingüísticos del texto. En cuanto a la fonética y la fonología, hay evidencia de características asociadas con las variedades meridionales peninsulares. Según la tesis andalucista (véase Frago Gracia, 1993; Penny, 2000: 138-151), estos rasgos se llevaron a las Américas y así contribuyen a la formación de la nueva koiné americana. En la Relación se encuentra una clara neutralización de las fricativas alveolares y de las africadas dentales medievales: aderesados 'aderezados' ${ }^{10}$, alsaronse 'se alzaron', biçitaron 'visitaron', confuçion 'confusión', conuerçion 'conversión', chosa 'choza', hermoça 'hermosa', rriquesas 'riquezas', siruelas 'ciruelas', solas 'solaz'. Se localizan ejemplos de aspiración y pérdida de /-s/ implosiva: la[s] fatales, lo[s] honbres, mu(r)[s]lo 'muslo', y[s]las y la forma ultracorrecta Quisuira 'Quivira'; así como de /-n/ final débil o nasalizada: las formas ultracorrectas acontencio 'aconteció'

\footnotetext{
${ }^{8}$ En esta cita alteramos la puntuación de la transcripción de Kania, Kauffeld y Sanz-Sánchez (2017).

9 Los hopi son otra tribu pueblo; véase el mapa en Kessell (2002: 38).

10 En este apartado no se cita el folio de los ejemplos. Consúltese la concordancia disponible en línea.
} 
y arronjole 'le arrojó', además de dema[n]da, e[n], estorba(n)ban, hallaria[n], quita[n]do, rra[n]cherias; neutralización de /-r/ y /-1/ finales: balbacoas, mu(r) [s]lo 'muslo'; y aspiración de $h$ - inicial: jasta 'hasta', aunque es posible que esta voz tuviera una pronunciación aspirada en el castellano también.

Otros rasgos fonológicos son comunes a los textos de la época a ambos lados del Atlántico, tales como la vacilación de vocales átonas (cfr. Penny, 2000: 133-134, 211; Cano Aguilar, 2004: 825-827; Torrens Álvarez, 2007: 260) y de grupos consonánticos latinos (cfr. Lapesa, 1981: 390; Lloyd, 1987: 350-351; Cano Aguilar, 2004: 852-853). Se observan ejemplos muy frecuentes de variación de vocales átonas como /e/ /i/: bedriada 'vidriada', discriçion 'discreción', entereçada 'interesada', intinçion 'intención', liçion 'lección', obidençia 'obediencia', siguirian 'seguirían' y tiniente 'teniente', así como algunos de /o/ /u/: munipudios 'monipodios', puliticas 'políticas'. La vacilación entre el mantenimiento y la reducción de grupos consonánticos se evidencia en ejemplos con grupo preservado, por lo menos en la ortografía, v. gr. cobdo, cognoçen, escripto, fructas, frente a ejemplos con grupo reducido, como condutas, esentos 'exentos', façion faiçion, solenidad.

La morfosintaxis del texto también revela rasgos típicos de la época (Lapesa, 1981: 393-408; Penny, 2002: 190-241; Girón Alconchel, 2004; Torrens Álvarez, 2007 : 261-262). Muchos verbos exhiben una morfología distinta a la del español moderno estándar, con pretéritos rizotónicos (bido 'vido', truxo ‘trujo'); imperfectos de ver en vía; formas del condicional con metátesis (pornia); uso del futuro perifrástico (deçirse an 'se dirán'); formas antiguas de haber (abemos perdido); e infinitivo + clítico con asimilación (lleuallo 'llevarlo'). En cuanto al uso de los verbos, el verbo haber se utiliza como transitivo para indicar posesión: "abemos gran dolor en el coraçon". Ser se usa como auxiliar de verbos intransitivos ("eran benidos a su tierra cristianos"); para denotar una condición que resulta de una acción ("su padre era muerto"); y para indicar lugar ("que sea en gloria"). Finalmente, el texto contiene ejemplos de diferencias en el orden sintáctico, específicamente la enclisis de pronombres átonos con verbos conjugados ("deleytanse en contar lo que bieron") y su proclisis con infinitivos y gerundios ("llegasen a se topar; aun no se fiando de esta gente").

\section{ESTUDIO LÉXICO}

\subsection{El léxico y la nueva realidad}

La necesidad de dar nombre "a las cosas, a la naturaleza, a las innumerables especies vegetales y animales descubiertas, a las actividades y organización de los distintos grupos etnoculturales" (Buesa Oliver y Enguita Utrilla, 1992: 29) exige que los conquistadores adaptaran la lengua a la nueva realidad. En una primera etapa del contacto, se bautizaban con nombres familiares o voces patrimoniales (indio, lagarto, piña, tigre) las realidades que iban encontrando, por aproximación 
y semejanza ${ }^{11}$ (Galeote López, 1992; Torres Torres, 2004). Sin embargo, el proceso de modificación de palabras patrimoniales es insuficiente puesto que ciertas realidades americanas se resisten a todo intento de identificación con aquellas del Viejo Mundo, de ahí que se incorporen préstamos de las lenguas indígenas, americanizando de este modo el español, tema del que nos ocupamos a continuación.

\subsection{Los indigenismos}

Pasamos a continuación a la descripción de los mecanismos de incorporación de palabras de fondo indígena en el texto: anona, areito, arcabuco, barbacoa, canoa, maíz, mezquite, nagua, petaca, petate, pinol, pitahaya, y por último, tuna. Para la realización de las entradas, se provee el fragmento del texto y se compara con textos coetáneos coloniales para profundizar en el estatus de la incorporación de la palabra en la lengua en el siglo XVI. Posteriormente, se ahonda en dos indigenismos, acochis 'oro' y papa 'sacerdote', ya que, a pesar de atestiguarse en el texto, no se incorporan en el español. La presentación de la información se organiza según la cronología de contacto con el español. Examinamos primero los tainismos, después los nahuatlismos y por último, las voces indígenas de la región de Cíbola.

\subsubsection{Tainismos ${ }^{12}$}

Anona ${ }^{13}$ 'árbol de la familia de las anonáceas, de unos cuatro metros de altura, de tronco ramoso, con corteza oscura, hojas grandes, alternas, lanceo-

11 Véase Bravo-García y Cáceres-Lorenzo (2011) para una panorámica general del proceso de incorporación, tipo de textos y autores.

${ }^{12}$ La procedencia del taíno de algunas voces clasificadas como tales no está ausente de cierta controversia. Se han clasificado así según se indicaba en alguna de las fuentes lexicográficas que se han manejado. Véase Álvarez Nazario (1992) sobre las lenguas indígenas en las Antillas y en el Caribe. Para una panorámica sobre el arahuaco y los tainismos, véase Enguita Utrilla (2010: 267-271).

${ }^{13}$ La disposición de las entradas léxicas es a saber: tras la definición se atiende al origen; seguidamente se proporciona el contexto en el que aparece la voz. Después de las citas se incluye un comentario sobre la documentación de la voz y su presencia en fuentes lexicográficas: Diccionario de la lengua española (DLE), Diccionario de americanismos (DAmer), Diccionario crítico-etimológico castellano e hispánico (DCECH), Nuevo diccionario de americanismos e indigenismos (NDAI), Diccionario del español de México (DEM), A Dictionary of New Mexico and Southern Colorado Spanish (Cobos, 2003), además de las obras de los lexicógrafos áureos, académicos y extraacadémicos disponibles en el Nuevo tesoro lexicográfico de la lengua española (NTLLE). Se han consultado puntualmente otras obras, que se indican en su momento. Asimismo, hemos acudido por su importancia y temática al Léxico hispanoamericano del siglo XVI (LHA), Corpus diacrónico del español (CORDE), Corpus del Nuevo diccionario histórico del español (CDH), y, por último, al Corpus Diacrónico y Diatópico del Español de América (CORDIAM). En casos puntuales se recoge alguna cita proporcionada por el $L H A, C O R D E, C D H$ o CORDIAM por su valor a la hora de completar el estudio léxico. No hemos tenido en cuenta un único contexto de aparición de las voces, sino varios (en caso de existir) en función del valor de los comentarios metalingüísticos. 
ladas, lustrosas, verdinegras por encima y más claras por el envés, flores de color blanco amarillento, solitarias...', 'fruto de la anona' (DLE). Este mismo diccionario sostiene que la voz procede del caribe, mientras que Buesa Oliver y Enguita Utrilla (1992: 63) la clasifican como tainismo. Anona no se documenta en $D C E C H$, aunque en él aparecen otras especies de la familia de las anonáceas como chirimoya y guanábano. El DAmer afirma que el término es de origen antillano (del arahuaco insular, caribe o taíno) y enumera varias acepciones metafóricas: 'hucha' o 'alcancía', 'prostituta' o 'cabeza de persona', confirmando así la tendencia de las designaciones indígenas de animales y vegetales a desarrollar sentidos figurados (Buesa Oliver y Enguita Utrilla, 1992: 225).

A pesar de que solo aparece una vez, el significado en este texto (1a) no deja lugar a dudas.

(1) a. ay ençinales de bellota dulce y fanonas que dan vna fruta como confites de culantro seco es muy dulce como asucar [fol. 104v].

b. el anón es la fructa muy mejor, aunque es muy menor [Fernández de Oviedo, Historia general y natural de las Indias, Ciudad de Santo Domingo, 1548; LHA].

c. árboles (...) de la tierra como son plátanos, aguacates, zapotes, e anonas, e mameyes e guayabas [México, 1564; LHA].

d. Una de ellas se llama eheyotzápotl; quiere dezir "tzapote cenziento o anonas", que tiene por de dentro unas pepitas como frixoles negros, y es muy sabrosa [Fray Bernandino de Sahagún, Historia general de las cosas de Nueva España, [México], 1576-1577; CDH].

e. Allá el manjar blanco es la anona o guanábana, que se da en Tierrafirme. Es la anona del tamaño de pera muy grande, y así algo abusada y abierta; todo lo de dentro es blando y tierno como manteca y blanco y dulce, y de muy escogido gusto. [José de Acosta, Historia natural y moral de las Indias, [España], 1590; CORDE].

La forma fanona de la Relación puede interpretarse, según Craddock (2010: 14), como una hipercorrección motivada por la aspiración y pérdida de la $f$ - ante vocal. La palabra aparece en el cap. 3 de la segunda parte, en la descripción de una zona que Castañeda denomina Chichilticale, en el sureste del actual estado de Arizona. El indigenismo aparece con una glosa explicativa de la fruta del árbol ${ }^{14}$, estrategia habitual en textos del primer periodo. Esta paráfrasis explicativa indica "que los indigenismos nombraban en el inicio del virreinato realidades nuevas y ajenas y requerían por ello de un apoyo, a manera de traducción, con los recur-

$14 \mathrm{Al}$ referirnos a los procedimientos de transmisión utilizados por Castañeda para incorporar los indigenismos en su texto, seguimos a Buesa Oliver y Enguita Utrilla (1992: 41-44), así como los trabajos Company Company (2012: 276-281) y Cáceres-Lorenzo (2014: 120-121). 
sos léxicos y gramaticales patrimoniales de la lengua que los estaba tomando en préstamo" (Company Company, 2012: 277).

La primera documentación de la voz, según el LHA (s. v. anón), se sitúa en 1548, en la forma masculina alternativa anón (1b); cfr. CORDE y $C D H^{15}$. Las documentaciones de anona son posteriores: en $L H A$ data de 1564 (1c) en un documento relativo a los bienes de Hernán Cortés, en $C D H$ es de 1576-1577 (1d) y en CORDE es de 1590 (1e). En CORDIAM hay dos ejemplos documentales de anón de 1582 (Puerto Rico) y uno de anona de 1767 (México), todos referidos al árbol.

Desde la perspectiva lexicográfica anona corre mejor suerte que pitahaya (por mencionar un ejemplo; véase la entrada más abajo) ya que Oudin la codifica por primera vez en $1607^{16}$, y a partir de ese momento se recoge en el Diccionario de autoridades $^{17}$ (NTLLE). La forma masculina anón no se codifica hasta 1770 en el diccionario académico con acepciones relacionadas tanto con el árbol como con la fruta, aunque afirma que anona es nombre más común para la fruta (NTLLE). Anón y anona están atestiguadas en LHA sobre todo en varias áreas tanto del México moderno durante el período colonial hasta el siglo XX, como también en distintas zonas de Colombia, Venezuela, Perú, Guatemala, Puerto Rico, República Dominicana y Cuba. Aunque hoy en día el árbol se cultiva en las costas del sur de España $(D L E)$, durante la época colonial la lexía constituía un americanismo ${ }^{18}$, a juzgar por la frase fruta de Indias en la definición de Autoridades.

Areito es una voz taína que hace referencia al 'canto y baile popular de los antiguos antillanos y centroamericanos, vivo en el repertorio de los ballets folclóricos', según el DAmer; cfr. DLE. Fernández de Oviedo facilita una ilustrativa explicación en la que posteriormente se basarán las fuentes lexicográficas para la definición del lema "cantares e bailes, que ellos llaman areito, que es lo mismo que nosotros llamamos bailar cantando" (LHA). En otros textos coloniales exhibe mucha variación gráfica y morfológica (aryto, areito, hareitos, areyte, areites). En

15 CORDE y $C D H$ proveen fechas de 1535-1557 para la obra de Fernández de Oviedo, $i$. $e$. fechas en que fue compuesta la obra, mientras que $L H A$ provee fechas según la cronología original del dato. Tanto $L H A$ como CORDE y $C D H$ se basan en las ediciones modernas del texto, de Juan de Pérez de Tudela y Bueso, publicadas en 1959 y 1992, respectivamente. Como es bien sabido, la información documental siempre es más fidedigna cuando se saca de textos editados filológicamente, $i$. e. no modernizados. Para la datación se debe considerar la fecha de producción específica de la obra, además de la fecha de producción original.

16 'Una sorte de fruict' (NTLLE).

17 'Fruta de Indias, espécie de membrillo del tamaño de una pera mui grande, y casi de su figúra, que se abre y hiende por la parte superiór. La carne es blanda y tierna como una manteca, blanca, dulce y mui sabrosa: las pepitas que tiene en medio son negras y en cantidad. Llamanle en Indias Manjar blanco, y por otro nombre Guanavana.' (NTLLE).

18 El término americanismo se aplica con un criterio contrastivo, en detrimento del etimológico: vocablo de uso particular en el español de las Américas. Para la problemática asociada con el término, véase Buesa Oliver y Enguita Utrilla (1992: 20-26). 
la época moderna la variación gráfica, e incluso fonológica, perdura, cfr. areyto, areíto (DAmer). El ejemplo de la Relación se provee en (2a):

(2) a. auia entre ellos hombres en abito de mugeres que se casaban con otros honbres y les seruian de mugeres canoni[ç]aban con gran fiesta a las mugeres que querian bibir solteras con vn grande areyto o bayle en que se juntaban todos los señores de la comarca y sacabanla a baylar en cueros [fol. 98r].

b. Yten, que no se pusiese impedimento a los indios en el hacer de los areitos en las fiestas, como lo tenían por costumbre; e así mesmo los días de labor, no dexando por ello de trabajar lo acostumbrado. [Alonso de Santa Cruz, Crónica de los Reyes Católicos, [España], 1491-1516; CDH].

c. Otrosy porque hemos seydo ynformados que sy se quitasen a los dichos yndios sus areytos e se les ynpidiese que no los hisyesen como suelen, se les haría muy de mal, hordenamos y mandamos que no se les ponga ni consyenta poner ningún ynpedimiento en el hazer los dichos areytos los domingos [Anónimo, Ordenanzas para el tratamiento de los indios, [Puerto Rico], 1513; $\mathrm{CDH}$ ].

d. (los) indios hizieron sus areytos e tajada a tajada (...) les fueron cortando las manos [Tierra Firme, 1515; LHA].

e. enlas dichas casas que eran dos o tres desde donde peleauamos tuuimoo la noche velando con mucho recado: \& no menos dedentro hizieron que toda la noche hizieron muy grandes areytos \& gritas \& tañendo atabales: \& muchas vezes nos tirauan piedra $\sigma$ \& algunas flechas: $\&$ se oya como arrancauan piedra para tirar porque sonaua al tiempo que la descargauan enel suelo. [Hernán Cortés, Cuarta carta de relación, Toledo, 1525; Kania y Gago Jover, 2018-].

La voz aparece en el cap. 1 de la segunda parte, en la descripción que Castañeda ofrece de Culiacán. Aparece con una glosa ecuacional (Company Company, 2012: 277; Cáceres-Lorenzo, 2014: 121) como sinónimo de baile ya que es una voz frecuente en los textos de la conquista ${ }^{19}$ tal y como sugieren las citas (2b-2e). La primera documentación que se ofrece en el $C D H$ de finales del siglo XV y principios del XVI (2b y 2c) es coetánea a la ofrecida por el LHA (2d). Aparece también en la Cuarta carta de relación de Hernán Cortés (2e).

Cabe notar que en los ejemplos (2b-2e) no se ofrece ningún sinónimo de areito; actuación que contrasta con el ejemplo cronístico de Fernández de Oviedo, así como con los ejemplos cronísticos encontrados en CORDIAM, de 1566 y 1568 en Ciudad de México, donde areito se equipara con 'baile' y 'danza'. Este tainismo se incorpora un siglo después en la lexicografía en 1617 en el diccionario de Minsheu ${ }^{20}$ (NTLLE), dos siglos después en el de Castro y Rossi (1852), Zerolo

19 De hecho, NDAI afirma que "Los conquistadores españoles difundieron la voz por toda América para significar danzas, cantos y fiestas en general de los indios".

20 'A kinde of dance among the Indians' (NTLLE). 
(1895) y la Academia (1899). Cabe apuntar que la definición de Zerolo marca el americanismo de anticuado ${ }^{21}$. Areito no se halla en DCECH. La voz es de uso corriente en Cuba y la República Dominicana tal y como ilustra CORPES en la acepción del DAmer. La variante areite perdura en la República Dominicana con la acepción 'alboroto, algarabía' (DAmer). Tanto en la época colonial como en la actualidad la voz representa un americanismo.

Arcabuco $^{22}$ 'monte muy espeso y cerrado' (DLE) constituye otro tainismo. Aunque el diccionario académico afirma que el origen del vocablo es incierto (quizá del taíno), en NDAI aparece etiquetado como tainismo. Para Corominas y Pascual es "probablemente" del taíno de Santo Domingo (DCECH), cfr. Buesa Oliver y Enguita Utrilla (1992: 57). El LHA provee una primera documentación de 1515 en Tierra Firme, lo cual adelanta quince años la primera aparición propuesta por CORDE y CDH, en la Relación de la conquista de los Teules chichimecas que dio Juan de Sámano de 1530 (México). CORDIAM también provee documentación de 1530 en un texto de la provincia de Santa Marta (Colombia actual). En LHA, se encuentran veintidós ejemplos de arcabuco entre los siglos XVI-XVIII en varias áreas de México y Colombia además de la República Dominicana, Guatemala, Venezuela y Panamá. En la Relación, el vocablo aparece en una única ocasión (3).

(3) el maestre de campo Lope de Samaniego con sierta compañia fue a buscar bastimentos y en vn pueblo por entrar indiscretamente por vn arcabuco en pos de los enemigos lo flecharon por vn ojo y le pasaron el çelebro de que luego murio alli [fol. 23v].

Se encuentra en el cap. 7 de la primera parte en la descripción de la llegada a Chiametla, en el actual estado de Sinaloa (México) y la posterior muerte del maestre de campo, Lope de Samaniego. El hecho de que no se parafrasee ni se glose en ninguno de los testimonios mencionados indica su nivel de integración en el léxico de los cronistas. El diccionario de Palet de 1604 introduce el lema por vez primera, definido como 'bocage espais', hecho que favorece su inclusión en Autoridades como 'lugar y sitio fragoso, barrancoso, y lleno de maléza y broza' (NTLLE). El DAmer lo marca como rural y de poco uso en República Dominicana y Puerto Rico. Aunque no se etiqueta de americanismo en Autoridades, las citas provistas están relacionadas con las Américas, señalando que la voz se asociaba más a las colonias que a la metrópoli en la época colonial.

El tainismo barbacoa se usa una vez en la Relación (4a), con el sentido de 'zarzo o tablado tosco en lo alto de las casas, donde se guardan granos, frutos, etc.' y 'zarzo cuadrado u oblongo, sostenido con puntales, que sirve de camastro' (DLE; cfr. Craddock, 2010: 18). Según $D L E$, la primera acepción forma parte del léxico de

21 'Nombre que daban los indios caribes de las Antillas y Venezuela á sus fiestas ó bailes. Es voz muy usada por los antiguos cronistas de América.' (NTLLE).

${ }^{22}$ Véase Galeote López (1992: 562-564) para documentación literaria y científica del indigenismo. 
Cuba, Ecuador y la República Dominicana, mientras que la segunda se asocia con Ecuador y Perú; cfr. DAmer y NDAI. Se documentan ambas acepciones en la obra de Fernández de Oviedo $c a$. 1535-1557, citada tanto por el LHA como por CORDE y $C D H$ (4b y 4c); cfr. CORDIAM que ofrece documentación de ca. 1565 de Historia de los indios de la Nueva España de fray Toribio de Benavente "Motolinía" (México).

(4) a. tienen los pueblos a la manera como los de la Nueba España las casas son rredondas sin çerca tienen vnos altos a manera de balbacoas por baxo la techunbre adonde duermen y tienen sus aberes [fol. 122v].

b. Ponen sus cuerpos, con todo el oro que tienen, en sus santuarios y casas de oración, en ciertas camas que los españoles allá las llaman barbacoas, que son lechos levantados sobre la tierra en puntales [Fernández de Oviedo, Historia general y natural de las Indias, [España], 15351557; $\mathrm{CDH}]^{23}$.

c. Son gente bien proveída, e guardan los bastimentos para entre tanto que cogen, e tienen otros en cámaras altas o barbacoas levantadas sobre la tierra un estado [Fernández de Oviedo, Historia general y natural de las Indias, [España], 1535-1557; $C D H$ ].

A la luz de las citas se puede extraer aspectos de relieve: en primer lugar, Fernández de Oviedo emplea una glosa explicativa en el primer ejemplo y una glosa ecuacional (cámara alta) en el segundo. En segundo lugar, Castañeda emplea el indigenismo barbacoas para explicar un concepto que no está totalmente explícito en altos. En este caso utiliza una glosa inversa ${ }^{24}$, un procedimiento sin duda innovador, únicamente documentado hasta el momento en textos del siglo XVIII (Company Company, 2012: 278), ya que se trata de una inversión del explanans-explanandum en la jerarquía del léxico donde el indigenismo explica la voz patrimonial. Por otro lado, la adición de la glosa inversa va en consonancia con lo descrito por Fernández de Oviedo, puesto que barbacoa era habitual en "los españoles allá" para referirse al significado autóctono. La palabra no aparece codificada hasta 1846 en el diccionario de Salvá: barbacoa 'zarzo que levantado del suelo con unas horquillas, sirve para varios usos', marcada como americanismo. Salvá también incluye balbacoa 'sobrado ó cámara que hay en las casas de los labradores, para guardar los aperos, granos y otros objectos', asociada con Cuba. La Academia incluye el americanismo barbacoa en su diccionario a partir de 1884 'carne asada en un hoyo que se abre en tierra y se calienta como los hornos'; las acepciones descritas arriba no se incorporan hasta 1914. Por la información metalingüística se deduce que barbacoa era un americanismo durante la época colonial. Las acepciones vistas en la Relación siguen siendo americanas; hoy en

\footnotetext{
${ }^{23}$ En LHA, esta cita se data en 1538 (Nueva Granada).

${ }^{24}$ Véase Company Company (2012: 278-279) para la caracterización de las glosas inversas tan habituales en el siglo XVIII.
} 
día, la voz es de uso general solo en las acepciones relacionadas con la parrilla y la comida asada en la misma.

Canoa 'embarcación de remo muy estrecha, ordinariamente de una pieza, sin quilla y sin diferencia de forma entre proa y popa' $(D L E)$. Este diccionario considera que el vocablo es un préstamo del taíno mientras que $D C E C H$ se inclina por el arahuaco de las Lucayas; cfr. Buesa Oliver y Enguita Utrilla (1992: 53-54) y NDAI. Mucho se ha escrito sobre este indigenismo por ser uno de los primeros documentados (en 1492 en el Diario de Colón) y el primero en codificarse (en 1495 en el Vocabulario español-latino de Nebrija), hecho que garantiza su aparición en el Thesoro de Covarrubias y en Autoridades (DCECH; NTLLE). Nebrija nota en 1495 que la canoa es una 'nave de un madero', Covarrubias que es 'ordinariamente de una pieza' y Autoridades 'regularmente... de una pieza', descripción que sigue usándose en la definición moderna. El tainismo se usa dos veces en la Relación (5a y 5b):

(5) a. deçia que auia en su tierra vn rrio en tierra llana que tenia dos leguas de ancho adonde auia peçes tan grandes como cauallos y gran numero de canoas grandissimas de mas de a ueinte rremeros por banda y que lleuaban uelas [fol. 53v].

b. deçian que se decia lo primero del poblado Haxa y que el rrio era de mas de vna legua de ancho y que auia muchas canoas [fol. 78v-79r].

El ejemplo de (5a) se ubica en el cap. 13 de la primera parte; aquí Castañeda relata la descripción que ofrece El Turco de Quivira. El ejemplo de (5b) es del cap. 19 de la primera parte, otro ejemplo de estilo indirecto en el que Castañeda expone lo que los querechos afirman sobre las tierras del este. Por el contexto de uso de canoa, i. e. sin glosa, no cabe duda de su completa integración en la lengua. De hecho, es uno de los pocos indigenismos en la Relación de uso general en ambos lados del Atlántico; es decir, no es un americanismo.

En esta misma línea de tainismos bien conocidos encontramos maíz $z^{25}$. DLE lo define como una 'planta de la familia de las gramíneas, con el tallo grueso, de uno a tres metros de altura, según las especies, hojas largas, planas y puntiagudas, flores masculinas en racimos terminales y las femeninas en espigas axilares resguardadas por una vaina. Es indígena de la América tropical, se cultiva en Europa y produce mazorcas con granos gruesos y amarillos muy nutritivos', 'grano de maíz'. Según Corominas y Pascual, la palabra viene del taíno de la isla de Haití mahís y se documenta en 1500 en el Diario de Colón como maiz $^{26}$. En las obras de Fernández de Oviedo y fray Bartolomé de Las

25 Véase Galeote López (1992: 242-255) para documentación literaria y científica del préstamo.

${ }^{26}$ Las Casas, por el contrario, afirma que es de La Española (DCECH). Por su parte, DAmer ofrece que el vocablo es de origen antillano, sin especificar una lengua en particular, mientras que NDAI lo considera un tainismo. 
Casas la voz se escribe con $h$ (mahiz) que todavía se aspira en algunos dialectos caribeños. Sin embargo, la forma sin $h$ pronto llegó a predominar (DCECH). CDH provee una primera documentación de 1495 (mahíz) en la Carta de Colón a los Reyes Católicos, pero en realidad no se conoce con exactitud la datación de la carta. La documentación de LHA es posterior (data de 1513 en Puerto Rico y Tierra Firme), al igual que la de CORDE, donde los primeros ejemplos son de las Cartas de relación de Cortés de 1519-1526; cfr. CORDIAM, que ofrece una primera documentación de maiz de 1525 (Ciudad de México). En la Relación el vocablo aparece seis veces, hecho que subraya la importancia del alimento para los españoles. Las grafías atestiguadas son mais, maix y maiz. Los primeros cuatro ejemplos textuales se proveen en (6).

(6) a. llego la gente de pax diciendo que ellos benian a dar la obidençia por toda la prouinçia y que los querian tener por amigos que rrecibiesen aquel presente que les daban que era alguna rropa de algodon aunque poca por no lo aber por aquella tierra dieron algunos cueros adobados y mucha harina y piñol y mais y abes de (de) la tierra [fols. 44r-44v].

b. en lo alto auia espacio pa sembrar y coger gran cantidad de maix y cisternas para rrecoger nieue y agua [fol. 50r].

c. dieron gran cantidad de gallos de papada muy grandes mucho pan y cueros de benado adobados y piñoles y harina y mais [fol. 50v].

d. por esto los abia desrrumbado creyendo que no supieran caçar ni mantenerse sin maiz [fol. 87v].

Los ejemplos en (6a y 6c) muestran la dependencia de los "regalos" de los indios para el sustento de los españoles. El ejemplo (6a) pertenece al cap. 11 de la primera parte, en el que se detallan las interacciones con los hopi. El ejemplo (6c) es del cap. 12 de la primera parte, en la parada en Ácoma de camino a los llanos de Cíbola. De hecho, esta dependencia alimenticia inspira a El Turco a intentar desviar a los españoles, ya que consideraba que no podrían sobrevivir sin la ayuda de los indios según ilustra el ejemplo (6d) (del cap. 21 de la primera parte). En esta época y en las posteriores, los españoles demandan víveres, ropa y otros productos a los indios, hecho que provoca tensiones debido a la escasez de recursos para su supervivencia ${ }^{27}$.

En cuanto a la incorporación de la voz, los ejemplos del texto muestran que maíz forma parte del léxico, y por tanto, se usa sin glosa, aunque aparece en el contexto de otros alimentos en (6a y 6c). Maíz se codifica en el diccionario de

${ }^{27}$ Un ejemplo de un conflicto causado por estas demandas lo encontramos en Ácoma en diciembre de 1598. Juan de Zaldívar, sobrino de Juan de Oñate y maestre de campo del ejército, paró en Ácoma de camino al descubrimiento del Mar del Sur (i. e. Océano Pacífico). Se cuenta que, descontentos por las continuas demandas, los indios atacan a los españoles y matan a trece personas, incluido el maestre de campo. El origen del conflicto parece encontrarse en el supuesto robo de un pavo a una mujer indígena por parte de un español. Véase Kania $(2013: 296,302)$. 
Covarrubias y aparece también en el primer diccionario de la Academia (NTLLE). Sin embargo, la definición de Covarrubias muestra que la voz no se considera parte del léxico peninsular estándar: 'una suerte de panizo que haze vnas mazorcas, y en ellas vnos granos amarillos, o roxos, tamaños como garuanços, delos quales molidos haze pan la infima gente'. El uso del maíz molido para hacer pan se repite en la entrada de Autoridades. Además, la autoridad de la voz se extrae de la obra del Inca Garcilaso: "De la harina del maíz hacen las Españolas los bizcochillos y fruta de sarten, y qualquiera otro regalo" (NTLLE). A pesar del uso del vocablo en textos peninsulares del siglo XVIII (cfr. Ramírez Luengo, 2017), es probable que se considerara como americanismo hasta bien entrada la centuria ilustrada.

Nagua es voz del taíno que alude a la 'prenda interior femenina, similar a una falda y que se lleva debajo de esta' (DLE: s. v. enagua; DAmer: s. v. nagua $)^{28}$. El DAmer añade una segunda acepción 'saya o falda', marcada como obsoleta, en México, El Salvador, Nicaragua y Costa Rica. Con respecto a la variación entre nagua y enagua, el DCECH afirma que la /e-/ se introdujo por aglutinación en las frases como estaba en nagua, salió en naguas, evitando así el que en tales casos pudiera entenderse en aguas. La primera documentación según el LHA, tanto de la variante nagua como la moderna enagua, se atestigua en 1512 en un documento de Puerto Rico, corpus que adelanta las documentadas tanto en $C D H$ (s. v. nagua) como en CORDE (s. v. enagua), el primero en 1519 en la Suma de geografía que trata de todas las partidas y provincias del mundo de Martín Fernández de Enciso y la segunda en 1615-1645 en Bailes de Quevedo. En CORDIAM se documenta enaguas en 1546 en un documento jurídico de Ocuilan, en el actual estado de México. Este préstamo se incorpora, al igual que otros de la Relación, en pasajes que describen las actividades y costumbres de los nativos (7):

(7) Señora es vn rrio y ualle muy poblado de gente muy dispuesta las mugeres bisten naguas de cuero adobado de benados y sanbenitillos hasta medio cuerpo [fol. 101v].

La voz aparece en el cap. 2 de la segunda parte, en la descripción de los indios de Petatlán, antiguo nombre de la provincia de Sinaloa (cfr. De Mora, 1992: 112, nota 153). La ausencia de glosa revela que naguas está plenamente integrado en la lengua. Se trata de un tainismo de pronta incorporación en la lexicografía hispánica, si se compara por ejemplo el caso de mezquite (como veremos más adelante), pues aparece en el Diccionario de autoridades 'género de vestido hecho de lienzo blanco, à manera de guardapiés, que baxa en redondo hasta los tovillos, y se ata por la cintúra, de que usan las mugéres, y le trahen ordinariamente debaxo de los demás vestidos' (NTLLE). La denominación era de uso general en la península, i. e. no tenía connotación de americanismo, y el mismo Quevedo autoriza la voz.

${ }^{28}$ DAmer origen antillano, DLE del taíno, DCECH del taíno de Santo Domingo. 
Pitahaya ${ }^{29}$ 'planta de la familia de las cactáceas, trepadora y de flores encarnadas o blancas según sus variedades. Algunas dan fruto comestible' (DLE). El DAmer le otorga varias acepciones, la primera referida a la planta ${ }^{30}$, la segunda al fruto $^{31}$ y la tercera hace referencia a otra especie de cactus de Guatemala y Puerto Rico ${ }^{32}$. Es de origen antillano, según este mismo diccionario; cfr. NDAI, que lo considera del arahuaco. Corominas y Pascual, sin embargo, consideran que pitahaya es "indudablemente" del taíno (DCECH: s. v. pita); cfr. Buesa Oliver y Enguita Utrilla (1992: 63-64). De las acepciones ofrecidas por DAmer, la lexía tiene poco uso en la primera y tercera acepción y es general en la segunda (Buesa Oliver y Enguita Utrilla 1992: 63-64) ${ }^{33}$. Aparece en dos ocasiones en el texto de Castañeda (8a y 8b):

(8) a. desde Petlatlan hace rraya aquella tierra cognoçidamente la causa porque desde alli para adelante no ay arbol sin espina ni ay frutas sino son tunas y mesquites y pitahayas [fol. 101r].

b. beben bino de pitahayas que es fruta de cardones que se abre como granadas [fol. 102v].

Ambas apariciones se hallan en el cap. 2 de la segunda parte, que corresponde a la descripción de Petatlán. En ambos casos Castañeda contextualiza el uso de pitayaha: en $8 \mathrm{a}$, explica indirectamente que se trata de una fruta y lo coordina con otras frutas indígenas. En 8 b la define como 'fruta de cardones', ya que era habitual en la época la utilización de cardo o cardón para referirse a algunas plantas autóctonas de las Américas, sobre todo para aludir a pitahayas y magueyes (cfr. DCECH: s. v. pita).

Pitahaya se documenta por primera vez en la Apologética historia sumaria (1527-1550) de Las Casas y en la obra de Fernández de Oviedo (1535-1557) según CORDE y $C D H$, fecha coetánea a la ofrecida por el $L H A$, con ejemplos que datan de 1548. CORDIAM ofrece documentación de ca. 1550 en Crónica del Perú de Pedro Cieza de León. Muy tardía es la inclusión del préstamo en la

\footnotetext{
29 Véase Galeote López (1992: 548-550) para documentación literaria y científica.

30 'Cactus perenne, trepador, con hojas carnosas de color verde, angulosas y armadas de espinas, flores de color blanco y fruto en baya, cuya pulpa es comestible' Selenicerus megalantus, Hylocereus spp. (DAmer). Cfr. De Mora (1992: 113-114, nota 156 y 161).

31 'Fruto de la pitahaya, de forma oblonga o redonda y de color rojo o amarillo, según la especie, con pequeñas espinas en la cáscara, y pulpa consistente y espumosa, de sabor dulce, con diminutas semillas negras' (DAmer). Cfr. De Mora (1992, 113-114, notas 156 y 161).

32 'Cactus de hasta $2 \mathrm{~m}$ de altura, con tallo ramoso y flores de color blanco, grandes y olorosas; crece regularmente sobre rocas o árboles', Cactus grandiflorus, Cereus triangularis (DAmer).

33 Curiosamente, NDAI afirma que entre los cronistas de Indias se mostraba inseguridad sobre si pitahaya correspondía a la planta o al fruto. En DEM la acepción relacionada con el fruto es la primera (s. v. pitaya); en México la forma sincopada es la usual.
} 
lexicografía, en 1846 en el diccionario de Salvá34 (NTLLE). Un recorrido por las entradas lexicográficas deja claro que se considera un americanismo. La palabra está atestiguada en LHA sobre todo en varias áreas del México moderno durante el período colonial y hasta el siglo XX, así como en Santo Domingo, Venezuela, Puerto Rico, Guatemala, Ecuador y Bolivia. La variante pitajaya se usa en diversas zonas de las Américas según DAmer. No obstante, no se reconoce su uso en los Estados Unidos, a pesar de formar parte del léxico de Nuevo México y el sur de Colorado, cfr. Cobos (2003) 'a plant of the Cactus family', donde se provee la siguiente cita: "The cactus that is usually called pitajaya in New Mexico is Echinocereus paucispinus" de Leonora S. M. Curtin en Healing Herbs of the Upper Rio Grande, pág. 157.

Para concluir con los tainismos, tuna hace referencia a la 'planta de hasta 5 $\mathrm{m}$ de altura, de tallos carnosos planos y ovados, normalmente con espinas, flores grandes amarillas o rojas y fruto en racimo; el fruto y los tallos aplastados son comestibles; se usa en la medicina tradicional. (Cactaceae; Opuntia spp.)', 'fruto comestible de la tuna, con forma de baya de color amarillo o púrpura' (DAmer). Este mismo diccionario afirma su origen antillano, aunque el $D C E C H$ especifica que proviene del taíno de Haití, cfr. NDAI y Buesa Oliver y Enguita Utrilla (1992: 62). Estos cactus son nativos de Cuba y Nueva España, tanto silvestres como cultivados. Los frutos formaban parte del sustento de la población indígena, de ahí que los cronistas los describan desde el principio (Galeote López, 2002: 113114). En el texto de la Relación aparece en tres ocasiones (9a-9c):

(9) a. en vna prouinçia que se diçe Uacapan auia gran cantidad de tunas que los naturales haçen conserua de ellas en cantidad [fol. 39v].

b. desde Petlatlan hace rraya aquella tierra cognoçidamente la causa porque desde alli para adelante no ay arbol sin espina ni ay frutas sino son tunas y mesquites y pitahayas [fol. 101r].

c. haçen conserua de tunas en gran cantidad conseruanse en su sumo en gran cantidad sin otra miel [fol. 102v].

El ejemplo de (9a) aparece en el cap. 10 de la primera parte, en la descripción del viaje de la retaguardia a Cíbola, y los ejemplos (9b y 9c) en el cap. 2 de la segunda parte. Todos se relacionan con zonas de México donde el cactus es nativo: Sonora en el caso de (9a) y Sinaloa en (9b y 9c). Como es evidente por el contexto, Castañeda lo utiliza sin paráfrasis alguna salvo una aclaración sobre su utilización por parte de los nativos.

Las primeras atestiguaciones de la denominación se encuentran en la prosa de Pedro Mártir de Anglería (1514-1516) y Fernández de Oviedo (1526) (Galeote

34 'Árbol de América cuyas ramas son á modo de cirios estriados, y salen derechas de su tronco sin hoja alguna. La fruta, que parece á los higos de tuna, nace pegada á las mismas ramas. Cactus pitahaya.' (NTLLE). 
López, 2002: 113-114). El LHA lo documenta por primera vez en 1532 en las Crónicas de la conquista de Nueva Galicia en territorio de la Nueva España y el $C D H$ y $C O R D E$ en 1536-1541 en la obra de Benavente; cfr. CORDIAM, que data el texto Benavente de $c a$. 1565. Se trata de un indigenismo de rápida incorporación en la lexicografía ya que fray Alonso de Molina lo introduce en su Vocabulario en lengua castellana y mexicana de 1555; define el náhuatl nopalli mediante este tainismo: "Nopalli nicteca. Plantar hojas, o ramas de tuna" [fol. 73v] (Galeote López, 2002: 113-114). Como consecuencia de la inclusión en el diccionario de Molina pasa a codificarse en el diccionario de Vittori (1609) y en Autoridades (1739) (NTLLE). Cabe, por último, señalar que la definición de Autoridades 'el fruto de la higuera de Indias: y tambien se llama assi el mismo arbol' (NTLLE) sirve de base a las acepciones académicas modernas, que siguen usando la extensión semántica de higuera e higo para aludir tanto a la planta como a la fruta ${ }^{35}$ (DLE: s. v. higo).

\subsubsection{Nahuatlismos ${ }^{36}$}

Mezquite 37 'árbol de América, de la familia de las mimosáceas, de copa frondosa y flores blancas y olorosas en espiga. Produce goma, y de sus hojas se saca un extracto que se emplea en las oftalmias, lo mismo que en el zumo de la planta.', del náhuatl mizquitl (DLE), que en su adaptación al castellano, la vocal /i/ pasa a /e/ tanto en la sílaba inicial (incluso trabada por consonante) como en la final (Hernández, 1998: 8). La africada lateral $t l$ (con $l$ sorda) en posición final de sílaba se reduce a $-t e^{38}$ (Rosenblat, 1967: 141). Aparece dos veces en la Relación, con una única variante inalterable, como ejemplifican los pasajes (10a y 10b).

Como en el caso de pitahaya y tuna, el indigenismo se usa para la descripción de Petatlán (i. e. Sinaloa) en el cap. 2 de la segunda parte. El árbol es nativo de México y del suroeste de los Estados Unidos. Se usa sin glosa junto con otros dendrónimos en el primer caso y con una frase explicativa indirecta en el segundo. El árbol pertenece a la familia de las leguminosas (De Mora, 1992: 114, nota 162; Cobos, 2003; DEM). Cabe señalar que el mezquite era muy importante para los indígenas del norte de México y suroeste de los Estados Unidos ya que se trata de una especie resistente a la sequía, que servía tanto como material de

\footnotetext{
35 Tuna 'higuera de tuna', 'higo de tuna' (DLE); cfr. higuera de tuna 'nopal', higuera de Indias 'nopal' (DLE: s. v. higuera) e higo de tuna 'fruto del nopal o higuera de Indias. Es verde amarillento, elipsoidal, espinoso y de pulpa comestible.' (DLE: s. v. higo).

${ }^{36}$ Para una panorámica del náhuatl, véase Enguita Utrilla (2010: 271-273).

37 Véase Galeote López (1992: 538-539) para documentación literaria y científica.

${ }^{38}$ Rosenblat (1967: 141) facilita, además, los siguientes ejemplos: tómatl > tomate; huexólotl $>$ guajolote 'pavo'; tzopílotl $>$ zopilote 'buitre'; ahuácatl $>$ aguacate; achíotl $>$ achiote o achote 'bija'; tecólotl > tecolote 'lechuza'.
} 
construcción como para la alimentación, puesto que el fruto es comestible (NDAI: s. v. mesquite). Las vainas se muelen para hacer la harina del pan, según puede apreciarse en la cita (10b).

Santamaría (1974) describe prolijamente los usos medicinales de la planta y sus partes, como ingrediente de varias bebidas así como la costumbre de tostar las semillas y mezclarlas con el café (cfr. Cobos, 2003), dato basado en un documento del LHA de 1532: "el brebaje que tienen es de unos árboles que tienen que se dize mezquites que dan unas algarrobillas delgadas" de Crónicas de la conquista de Nueva Galicia en territorio de la Nueva España ${ }^{39}$. La documentación de CORDE y la de CORDIAM (s. vv. mesquite, mezquite) es bastante posterior, de finales del XVI y principios del XVII. La forma mezquiquez se atestigua en La relación de Cabeza de Vaca en 1542 (10c).

(10) a. desde Petlatlan hace rraya aquella tierra cognoçidamente la causa porque desde alli para adelante no ay arbol sin espina ni ay frutas sino son tunas y mesquites y pitahayas [fol. 101r].

b. haçen pan de mesquites como quesos conseruase todo el año [fol. 102v]. c. \& dauan nos mucha harina de Mezquiquez. este Mezquiquez es vna fruta que quando esta enel arbol es muy amarga y es d[e]la manera de Algarrouas / \& comese con tierra \& con ella esta dulçe \& bueno de comer [Álvar Núñez Cabeza de Vaca, La relación, Zamora, 1542; Kania y Gago Jover, 2018-].

Mezquite está atestiguado en LHA en varias áreas del México moderno desde el período colonial hasta el siglo Xx y forma parte del léxico de Nuevo México (Cobos, 2003). Este nahuatlismo no se recoge ni en el diccionario de Covarrubias ni en Autoridades ni en DCECH debido, sin duda, a su marcado regionalismo adscrito en particular a la variedad mexicana, así como a la especialización de su contenido. Por lo tanto, se trata de un lema escasamente documentado en textos de lengua general: CORDE lo atestigua en tan solo tres documentos; con grafía mezquite lo encontramos únicamente en nueve documentos. No obstante, las fuentes lexicográficas lo codifican por primera vez en 1787, en el Diccionario castellano con las voces de ciencias y artes de Terreros y Pando, como no podía de ser de otra manera, al tratarse de una voz técnica, 'cierta madera de Californias', y la Academia lo incorpora en la duodécima edición (1884) (NTLLE).

Petaca 'maleta o pequeño arcón de madera o forrado de cuero para viajar o llevar una carga' (DAmer); ' arca de cuero, o de madera o mimbres con cubierta de piel, a propósito para formar el tercio de la carga de una caballería. Se ha usado mucho en América.' (DLE). La definición de $D L E$ incluye un detalle importante,

\footnotetext{
${ }^{39} \mathrm{Cfr}$. $\mathrm{CDH}$, que tiene documentación relacionada pero datada en 1544, la Segunda relación anónima de la jornada que hizo Nuño de Guzmán a la Nueva Galicia.
} 
i. e. la inclusión de mimbre como uno de los materiales ya que la palabra se basa en el náhuatl petlatl 'estera' + calli 'casa' (cfr. Craddock, 2010: 6; DCECH: s. v. petate). En petaca < petlacalli 'caja hecha de petate', el sonido dentoalveolar lateral africado sordo /tl/, inexistente en el sistema fonológico del español, se introduce con cierta inestabilidad, y origina resultados polimórficos dependiendo de su posición en la palabra (Hernández, 1998: 12-13). En posición inicial, como es el caso, pasa de [tl] > [t]. En sílaba final del étimo náhuatl se produce una apócope $^{40}$,-lli $>\varnothing$ (Hernández, 1998: 17). Se trata de una de las muchas voces aztecas de productos y realidades desconocidas en las islas antillanas que entraron en el uso común y se propagaron por todo el ámbito hispano y las lenguas europeas.

En la Relación (11a) la voz se usa en el cap. 3 de la primera parte, cuando Castañeda describe la expedición de fray Marcos de Niza. Como se usa sin explicaciones y, además, en la descripción de las actividades de los españoles, la denominación parece ser común en el español de Nueva Galicia de la época (entre 1530 y 1560). La definición del dominico Las Casas en su Historia de las Indias (11b) sirve de base para la definición de la que partirán las distintas fuentes lexicográficas.

(11) a. pusieronlos en tanto temor que aun no se fiando de esta gente con aber ydo en compañia del negro abrieron las petacas que lleuaban y les rrepartieron quanto trayan que no les quedo salbo los hornamentos de deçir misa [fol. 14v].

b. mandó el cacique a uno de los que con él habían venido, que sacase lo que dentro de una que llamamos petaca, según la lengua de México — que es como arca hecha de palma y cubierta de cuero de venado-, traía. [Fray Bartolomé de las Casas, Historia de las Indias, [España], ca. 1527-1561; $C D H]$.

Las primeras apariciones documentadas en $C D H, C O R D E$ y $L H A$ son coetáneas; se atestiguan en la obra de Las Casas citada arriba, en la de Fernández de Oviedo (1535-1557) y en textos relacionados con la conquista de Nueva Galicia ca. 1531-1532 (CDH, Relación de la entrada de Nuño de Guzmán, que dio García del Pilar, su intérprete de García del Pilar; LHA, Crónicas de la conquista de Nueva Galicia en territorio de la Nueva España). En CORDIAM encontramos una documentación con fecha similar - 1538 - en un documento jurídico de Tlapanaloya, en el actual estado de México.

El préstamo entra a formar parte de la lexicografía en 1591 en el diccionario de Percival $^{41}$. Autoridades lo define como 'especie de arca hecha de cueros ù pellejos f[u]ertes, ù de madéra cubierta de ellos', sin la etiqueta de americanismo bajo la

\footnotetext{
40 Entre otros ejemplos están: ciuatl + naualli > ciguanaba 'fanstasma en forma de mujer' y xahualli > jagua 'árbol de América intertropical' (Hernández, 1998: 17).

${ }^{41}$ La definición 'a basket, a hamper' enfatiza el material original de la petaca (NTLLE).
} 
autoridad, no obstante, de el Inca Garcilaso ${ }^{42}$. La voz tenía una vitalidad intermedia en el habla culta de México en las últimas décadas del siglo XX (cfr. Buesa Oliver y Enguita Utrilla, 1992: 142) y en la actualidad tiene vigencia en el español general con los significados 'estuche para llevar cigarros o tabaco picado' y 'botella de bolsillo que sirve para llevar bebidas alcohólicas' (DLE). La vitalidad histórica en el español de América se evidencia en la gran gama de usos figurados y eufemísticos, p. ej. 'joroba', 'vientre abultado' y en plural, 'nalgas' $(D A m e r)^{43}$. En la actualidad, además, forma parte del léxico de Nuevo México y el sur de Colorado, cfr. Cobos (2003) en la acepción de 'caja hecha de petate' uso que no está registrado en el DAmer. El indigenismo es, asimismo, un topónimo en el condado de Río Arriba, Nuevo México.

Petate es otra voz nahua 'esterilla hecha de ramas de palma tejidas para múltiples usos' (DAmer); proviene de petlatl 'estera' (DLE). Como se había mencionado con anterioridad, esta africada lateral /tl/ tan característica del náhuatl tiene distinta adaptación dependiendo de su posición; en posición intervocálica se redujo a $/ t^{44}$. La voz está, al igual que la anterior, muy extendida especialmente por México y América Central, así como en Puerto Rico, Colombia, Venezuela y Chile (DAmer). Petate aparece una vez en la Relación, en el cap. 2 de la segunda parte donde Castañeda describe Petatlán, i. e. Sinaloa (12):

(12) dixose Petlatlan por ser las casas de petates dura esta manera de casas por aquella parte docientas y quarenta leguas y mas que ay hasta el principio del despoblado de Çibola [fols. 100v-101r].

Al igual que el indigenismo petaca, no se ofrece ninguna explicación y además se usa el indigenismo para explicar la etimología del topónimo Petatlan. Según $D C E C H$, petate se testimonia por primera vez en documentación de 1531 en una narración relacionada con Culiacán, que es también el contexto geográfico que encontramos en nuestro texto ${ }^{45}$; cfr. LHA que provee documentación de 1532 de las Crónicas de la conquista de Nueva Galicia en territorio de la Nueva España. La voz alcanza mucha frecuencia en los cronistas de Indias, p. ej. en Las Casas y Sahagún (cfr. CDH; CORDE). Petate está documentado en CORDIAM en 1539 en un documento jurídico de la Ciudad de México.

\footnotetext{
42 "En aquellas petácas solian los Españoles traher, de camino y en las guerras, todo lo que tenian" (NTLLE).

43 Como explican Buesa Oliver y Enguita Utrilla (1992: 225-226) algunos americanismos adquieren "a parte de su sentido principal, acepciones figuradas que la tradición ha fijado entre los hispanohablantes del otro lado del Océano".

44 P. ej. métlatl > metate; petlacalli > petaca; tlaotlali > clotali 'cacique'; camotli > camote 'batata'; etc. (Rosenblat, 1967: 141).

45 Nuño de Guzmán descubre Petatlán en 1530, solo una década antes de la expedición de Vázquez de Coronado. Como indica De Mora "se llamó Petatlán por la forma y materiales con los que construían los indígenas sus casas: jacales o chozas hechas de paja y carrizo cubiertos con petates" (1992: 112, nota 153).
} 
A pesar de su temprana documentación, no se codifica en la acepción de estera hasta finales del siglo XVIII (Terrenos y Pando), curiosamente con referencia a Asia y Perú ${ }^{46}$. La Academia lo introduce a principios del siglo XIX 'en la América la estera que hacen y usan los indios de Nueva España' (NTLLE). Autoridades registra la acepción 'embustéro ù estafadór' (NTLLE), que sirve para ejemplificar el cambio semántico, que conlleva el menosprecio que experimentan algunos indigenismos de campos onomasiológicos concretos (Buesa Oliver y Enguita Utrilla, 1992: 225). El término posee otras acepciones, p. ej. 'equipaje para marinero u otro navegante' frecuente en la península, además de su aparición en la frase liar el petate 'marcharse' (DCECH). Esta voz tiene plena vigencia en el léxico de Nuevo México, cfr. Cobos (2003) 'mat'47, i. e. 'estera', región cuyas acepciones se ignoran en el DAmer. La acepción 'morir' se incluye también en DLE para la frase liar el petate.

Pinol $^{48}$ 'harina fina de maíz tostado', 'bebida refrescante, similar al chocolate, que se prepara con harina de maíz tostado, cacao, achiote y azúcar, cocidos y batidos', del náhuatl pinolli 'harina de maíz' (DAmer). Las denominaciones nahuas con el sufijo - $l l i$ pasan al español simplificadas de $l:>l$, la grafía del fonema lateral /1/ para el sonorante /1/ de pronunciación larga [1:], por un lado, y de pérdida de la $-i$ final, por el otro (Hernández, 1998: 16). Sin embargo, la variante con /-e/ final, $i$. e. pinole, se documenta desde la época colonial hasta nuestros días en México (DEM: s. v. pinole) donde es la forma preferida; cfr. atolli > atol, atole. Se trata de uno de los muchos términos relativos a la alimentación, en concreto de una bebida muy utilizada por los aztecas en sus viajes puesto que se bebe fría. Los exploradores españoles lo adoptaron rápidamente y se convirtió en una bebida tanto de la población hispánica como de los nativos norteamericanos (Smith, 2013: s. v. pinole). En la Relación aparece dos veces; en ambos casos en la acepción 'harina' (13a y 13b).

El ejemplo (13a) aparece en el cap. 11 de la primera parte en el que se narra el encuentro con los indios hopi; el ejemplo (13b) se refiere a los víveres provistos por los indios de Ácoma. El nahuatlismo aparece sin glosa dentro de una enumeración de alimentos. En los dos ejemplos la denominación aparece con la grafía palatal $\tilde{n}$ y no $n$, variante que debía ser común, ya que aparece también en las primeras documentaciones de LHA (s. v. pinol), p. ej. "una taleguilla de cacao Piñol", que se encuentran en un documento mexicano del Libro de las tasaciones

46 'Tejido mui curioso de palma, que usan en Asia para cortinas; y para poner en verano sobre los colchones, por ser mui fresco. En el Perú usan una especie de tejido de una planta ó yerba ancha, y mui suave que sirve como de alfombra, y tiene el mismo nombre' (NTLLE).

47 "Petate mats are made of dry strips of palm or other similar materials. In Colonial times petates served as floor coverings, mattresses and as a wrap for a cadaver being taken to the grave. Enrollar el petate, to roll the mat (to die)".

48 Véase Galeote López (1992: 651-653) para documentación literaria y científica. 
de los pueblos de la Nueva España con datación entre 1531 y 1544. Los primeros ejemplos que ofrece este corpus tienen el sentido de 'harina'; la acepción 'bebiba' se documenta en 1571 en el diccionario de Molina y posiblemente en 1568 en la Historia verdadera de la conquista de la Nueva España de Bernal Díaz de Castillo ( $L H A)$. CORDE y $C D H$ proveen primeras documentaciones de la obra de Fernández de Oviedo (1535-1557), un poco posteriores a las de LHA. CORDIAM proporciona un ejemplo de piñol (13c) de 1539, de la Relación de fray Marcos de Niza, muy similar al ejemplo (13a).

(13) a. dieron algunos cueros adobados y mucha harina y piñol y mais y abes de (de) la tierra despues dieron algunas turquesas aunque pocas [fols. 44r-44v].

b. dieron gran cantidad de gallos de papada muy grandes mucho pan y cueros de benado adobados y piñoles y harina y mais [fol. 50v].

c. me truxeron mucha caça de venados, conejos y codornizes y mayz y piñol, todo en mucha abundancia y me ofresçieron muchas turquesas y cueros de vaca y xicaras muy lindas y otras cosas de lo qual no tome nada [Fray Marcos de Niza, Relación de Fray Marcos de Niza, México, 1539; CORDIAM].

La denominación se codifica en 1853 en el diccionario de Domínguez, bajo cuya entrada afirma 'polvo aromático compuesto de varias sustancias, como vainilla, canela, etc., y que se echa en el chocolate para darle un sabor grato' (NTLLE). Dos años más tarde, el diccionario de Gaspar y Roig incluye la definición que acabamos de citar como primera acepción de pinole y para la segunda: 'la harina de maíz tostado; suele usarse desleída en agua con un poco de azúcar, y es bebida muy refrescante', marcadas como mejicanismos. La Academia lo incorpora por primera vez en 1927; pinole sigue siendo la forma principal, pero pinol se incluye también (NTLLE). Según DAmer, se usa el vocablo en México, América Central y Cuba, y al igual que en los nahuatlismos anteriores, se ignora el español de Nuevo México, cfr. Cobos (2003: s. v. pinole $)^{49}$.

\subsubsection{Préstamos de lenguas indígenas norteamericanas}

Acochis. Según Castañeda, los indios de Quivira utilizaban acochis para referirse al oro. Este es uno de los pocos ejemplos de préstamos léxicos procedentes de las lenguas indígenas de las zonas de Cíbola y Quivira, sin contar, claro está, con los topónimos o los gentilicios. La denominación se relaciona con una de las preocupaciones fundamentales: la búsqueda de riquezas, sobre todo, de meta-

49 'A kind of cornmeal made with parched corn which is ground as a fine cornmeal. As such, the pinole is fed to caged birds: cenzontles (mockingbirds), canaries, parrots, etc.' . 
les preciosos, según señala Parodi (2009: 495-496), que documenta tuob, caona, noçay y guanín para 'oro' en textos colombinos. Acochis corre la misma suerte que los anteriores antillanismos, pues no llegan a integrarse en el léxico ${ }^{50}$. Cabe la posibilidad de que Castañeda se equivocara en la equivalencia acochis y 'oro' ya que Hodge (1907: 337, nota 1) considera que puede que provenga de hakwichis 'metal'. De hecho, es probable que los indígenas de esas zonas supieran poco del oro cuando llegaron los españoles (cfr. De Mora, 1992: 108, nota 139; Craddock, 2010: 9). Lógicamente, no se codifica en ningún diccionario del español pero aparece dos veces en la Relación (14a y 14b):

(14) a. deçia mas quel comun seruiçio de todos en general era plata labrada y los jarros platos y escudillas eran de oro llamaba a el oro acochis [fol. 54r].

b. no benian satisfechos de creer que no auia oro antes trayan sospecha que lo auia la tierra adentro porque puesto que lo negauan entendian que cosa era y tenia nombre entre ellos que se decia acochis [fol. 94v].

El ejemplo (14a) aparece en el cap. 13 de la primera parte y forma parte de la descripción que El Turco ofrece de Quivira, cuyo objetivo era atraer la atención de los españoles. El ejemplo (14b) es del cap. 22 de la primera parte y constituye una de las últimas frases de ese segmento de la obra, lo que subraya la importancia del oro para los españoles.

Papa. Según Castañeda papa es la palabra que usan los indios hopi para referirse a un sacerdote. Aparece una vez en el texto, en el cap. 3 de la segunda parte (15):

(15) tienen sus saserdotes a quien llaman papas que les predican estos son uiejos [fol. 106r].

Según De Mora (1992: 118, nota 174) papa es una verdadera palabra zuni que significa 'hermano mayor'. Ignoramos si Castañeda equivocadamente atribuye la palabra a los indios hopi o si era una palabra en común en las dos culturas. A diferencia de acochis, papa 'sacerdote' se documenta en textos de la época. Encontramos este ejemplo en LHA, sacado de la obra de Díaz de Castillo datada en 1568: "sacerdotes de ídolos, que en la Nueva España comúnmente se llamaban papas". Como explican Corominas y Pascual, la voz papa 'pontífice' del español viene del latín PAPAS 'obispo' y este del griego (DCECH). En el griego pápas significaba 'sacerdote', 'obispo', 'papá' $(D L E)$. Tanto en latín como en griego, son "voces infantiles de creación expresiva, y pertenecen a un tipo de formación extendido en muchos idiomas de familias diversas" (DCECH). Es posible que los ejemplos de arriba de las lenguas indígenas también sean en origen voces de creación expresiva; la acepción 'sacerdote' de 'papá' es una extensión semántica común en muchas lenguas.

${ }^{50}$ Guanín, con la acepción 'joya', sobrevive en algunos dialectos caribeños (Parodi, 2009: 496). 


\section{CONCLUSIONES}

El presente artículo tenía como objetivo una profundización en el conocimiento de la Relación de la jornada de Cíbola, texto cronístico del siglo XVI que representa una obra relativamente poco conocida entre los estudiosos de la lengua española en la época colonial. Se trata de un texto interesantísimo, sin duda, desde varios puntos de vista, entre los que se pueden destacar el valor de la segunda parte de la Relación como modelo de representación geográfica y etnográfica ${ }^{51}$, con listas toponímicas de una nueva frontera en un desconocido continente. Estamos ante un cronista cosmógrafo cuyo lenguaje, en palabras de Ahern (1999: 60) "titubeaba ante la pluralidad y poderío del terreno americano". Se trata, asimismo, de la crónica de un testigo que pergeña un relato sobre la constatación de la derrota de una expedición, con una "trabajada estructuración y, en suma, una pensada poética del fracaso dirigida a un acto de promoción personal" (Escudero Baztán, 2015: 42).

Nuestro acercamiento léxico ha revelado un total de quince préstamos indígenas que Castañeda emplea para describir la nueva realidad americana. A través del análisis de la documentación de las voces en la época colonial y su posterior codificación, hemos mostrado que la mayoría de estas voces eran características del español americano en oposición al peninsular, y que, por lo tanto, contribuían a la indianización, o americanización, de la lengua durante la época colonial. De hecho, la mayoría de estas denominaciones siguen considerándose americanismos.

Se han analizado quince denominaciones, nueve tainismos (anona, areito, arcabuco, barbacoa, canoa, maíz, nagua, pitahaya, tuna), cuatro nahuatlismos (mezquite, petaca, petate, pinol) y dos préstamos de las lenguas indígenas del actual suroeste de los Estados Unidos (acochis, papa). Desde el punto de vista onomasiológico, seis se relacionan con las plantas y sus productos, $i$. e. frutos, granos, etc.: anona, maíz, mezquite, pinol, pitahaya, tuna; dos con la naturaleza: acochis, arcabuco; cinco con artefactos: barbacoa, canoa, nagua, petaca, petate; y dos con ritos o costumbres: areito, papa.

Desde el punto de vista de la integración de los préstamos en el léxico, cinco se usan en el texto sin glosa ni paráfrasis, índice claro de su incorporación a la lengua del siglo XVI, por lo menos al habla de Castañeda, arcabuco, canoa, nagua, petaca y petate, así como maíz y pinol, que aparecen dentro de enumeraciones. Areito y barbacoa aparecen con una glosa ecuacional, el primero e inversa, en el segundo caso. Por otro lado, seis préstamos se encuentran en contextos con explicaciones directas o indirectas (acochis, anona, mezquite, papas, pitahaya y tuna); el uso de paráfrasis de los significados de estas voces indígenas parece estar motivado por la consideración de que se trataba de voces desconocidas para el lector.

51 El pueblo mexica, el español, pueblos del desierto, de la costa de Sonora, pueblos de las mesetas altas del río Colorado, los varios grupos de las llanuras y los wichita (véase Ahern, 1999). 
Todas ellas y su grado de integración ya en el siglo XVI resultan interesantísimas porque arrojan luz, complementan datos y ayudan a establecer conclusiones pertinentes a estudios léxicos anteriores, dado que, en el caso particular de barbacoa se desconocía esta forma de glosar los indigenismos en textos cronísticos de ese siglo. Este tipo de hallazgos son un indicio de la importancia de estas fuentes documentales, tradicionalmente poco estudiadas, así como de su enriquecedor aporte para la compresión de la evolución léxica del español al otro lado del Atlántico.

La comparación de los datos textuales con la información metalingüística de diccionarios y otras fuentes proporciona conclusiones interesantes respecto al uso de las trece voces durante la época colonial (excluyendo acochis y papa por razones obvias). Entre los préstamos codificados en el s. XV está canoa; en el s. XVII maíz; en el s. XVIII anona, arcabuco, mezquite, nagua, petaca, petate, tuna; en el s. XIX areito, barbacoa, pitahaya, pinol. Respecto a las marcas lexicográficas, todas llevan la marca americanismo excepto arcabuco, canoa, nagua y petaca. Incluso el tainismo maíz, hoy en día uno de los indigenismos más usados en la lengua general, probablemente se consideró americanismo hasta bien entrado el s. XVIII, a juzgar por las citas de Covarrubias y de Autoridades. Lo mismo se puede decir de petaca, codificada en el s. XVIII pero posiblemente considerada como voz de uso en las Américas, otro ejemplo de los muchos diferenciadores entre la lengua de los "indianos" y de los usos peninsulares. Los únicos dos indigenismos documentados en la Relación de uso general en la época colonial son canoa y enaguas. El hecho de que en un testimonio relativamente breve se hallen esta cantidad nada desdeñable de indigenismos puede ser una estrategia para reforzar el grado de autenticidad del texto, esto es, de la experiencia de Castañeda (Cáceres-Lorenzo, 2013).

Nuestro análisis también ha puesto de relieve que la mayoría de los indigenismos registrados provienen del taíno, lengua que proporciona nueve de los quince, frente a cuatro del náhuatl y dos de las lenguas autóctonas del suroeste de los Estados Unidos. Estos datos corroboran la importancia de Antillas en el proceso de colonización (Enguita Utrilla, 2010: 268). Asimismo, el taíno también fue la primera lengua indígena en desaparecer (Enguita Utrilla, 2010: 267). Es posible que el mayor arraigo de los tainismos en la lengua española se deba al hecho de que dejan de asociarse a la cultura taína, i. e. a la cultura del Otro.

Cabe también mencionar que cinco denominaciones, en concreto los nahuatlismos aunque no exclusivamente, han servido para ilustrar la escasa atención con la que se ha atendido la variedad lingüística de español de Nuevo México en los Estados Unidos, ejemplo por antonomasia de una lengua minorizada.

Finalmente, este trabajo ha manifestado, una vez más, la importancia del acceso a textos históricos fielmente editados para poder aclarar cuestiones de la historia de la lengua en ambos lados del Atlántico. 


\section{BIBLIOGRAFÍA}

Ahern, Maureen (1999): "La narración cartográfica de La Relación de la Jornada de Cíbola", en Salvador García Castañeda (coord.), Literatura de viajes. El Viejo Mundo y el Nuevo. Madrid, Castalia, pp. 51-60.

Álvarez Nazario, Manuel (1992): “Lenguas indígenas en el Caribe y las Antillas”, en César Hernández Alonso (coord.), Historia y presente del español de América, Valladolid, Junta de Castilla y León, pp. 235-250.

Bravo-García, Eva y María Teresa Cáceres-Lorenzo (2011): La incorporación del indigenismo léxico en los contextos comunicativos canario y americano (1492-1550), Bern, Peter Lang.

Bravo-García, Eva y María Teresa Cáceres-Lorenzo (2014): "Estrategias comunicativas y tipos documentales en la selección de voces amerindias en el siglo XVI”, RILCE. Revista de filología hispánica, 30, 1, pp. 86-110.

Buesa Oliver, Tomás y José María Enguita Utrilla (1992): Léxico del español de América: su elemento patrimonial e indígena, Madrid, Mapfre.

Cáceres-Lorenzo, María Teresa (2013): "Indoamericanismos de uso general en documentos españoles americanos (1502-1560): propuesta de clasificación y resultados”, Bulletin of Spanish Studies, 90, 7, pp. 1079-1090, <https://doi.org/10.1080/14753820.2013.839141>.

Cáceres-Lorenzo, María-Teresa (2014): "Differentiation Between Indigenous Loanwords in the Spanish American Lexicon", Bulletin of Hispanic Studies, 91, 2, pp. 117-126, $<$ https://doi.org/10.3828/bhs.2014.8>.

Cano Aguilar, Rafael (2004): "Cambios en la fonología del español durante los siglos XVI y XVII", en Rafael Cano (coord.), Historia de la lengua española, Barcelona, Ariel, pp. 825-857.

$C D H=$ Instituto de Investigación Rafael Lapesa de la Real Academia Española (2013): Corpus del Nuevo diccionario histórico, <http://web.frl.es/CDH>.

Cobos, Rubén (2003): A Dictionary of New Mexico and Southern Colorado Spanish, ed. rev., Santa Fe, Museum of New Mexico Press.

Company Company, Concepción (2012): "El español del siglo XVIII. Un parteaguas lingüístico entre España y México", en María Teresa García Godoy (ed.), El español del siglo XVIII. Cambios diacrónicos en el primer español moderno, Bern, Peter Lang, pp. 255-291.

$C O R D E=$ Real Academia Española: Banco de datos [en línea]. Corpus diacrónico del español, $<$ http://www.rae.es>.

CORDIAM = Academia Mexicana de la Lengua: Corpus Diacrónico y Diatópico del Español, $<w w w$. cordiam.org $>$.

CORPES XXI = Real Academia Española: Banco de datos [en línea]. Corpus del Español del Siglo $X X I,<$ http://www.rae.es /recursos/banco-de-datos/corpes-xxi>.

Craddock, Jerry R. (1999): "Fray Marcos de Niza, Relación (1539): Edition and Commentary", Romance Philology, 53, 1, pp. 69-118, <https://doi.org/10.1484/j.rph.2.304335>.

Craddock, Jerry R. (2010): "Pedro de Castañeda y Nájera, Relación de la jornada de Cíbola: acotaciones gramaticales y léxicas", UC Berkeley, Research Center for Romance Studies, $<$ https://escholarship.org/uc/item/8dn472wk>.

Craddock, Jerry R. y John H. R. Polt (1999): Zaldivar and the Cattle of Cíbola, Dallas, William P. Clements Center for Southwest Studies, Southern Methodist University.

DAmer = Asociación de Academias de la Lengua Española (2010): Diccionario de americanismos, Madrid, Santillana.

DCECH = Joan Corominas y José Antonio Pascual (1980-1991): Diccionario crítico etimológico castellano e hispánico, Madrid, Gredos.

De Mora, Carmen (1992): Las siete ciudades de Cíbola. Textos y testimonios sobre la expedición de Vázquez Coronado, Sevilla, Alfar. 
DEM = Luis Fernando Lara (dir.) (2010): Diccionario del español de México, México, El Colegio de México, <https://dem.colmex.mx/>.

$D L E=$ Real Academia Española y Asociación de Academias de la Lengua Española (2014): Diccionario de la lengua española [en línea], 23a ed., Madrid, Espasa, <http://dle.rae.es/>.

Enguita Utrilla, José María (2010): "Capítulo 6. Formación de palabras", en Milagros Aleza Izquierdo y José María Enguita Utrilla (coords.), La lengua española en América: normas y usos actuales, Valencia, Universitat de València, pp. 261-315.

Escudero Baztán, Juan Manuel (2015): "La Relación de la Jornada de Cíbola de Pedro Castañeda de Nájera como una política del fracaso", Romance Notes, 55 Special Issue, pp. 35-43, $<$ https://doi.org/10.1353/rmc.2015.0035>.

Flint, Richard (2008): No Settlement No Conquest: A History of the Coronado Entrada, Albuquerque, University of New Mexico Press.

Flint, Richard y Shirley Cushing Flint (2005): Documents of the Coronado Expedition, 1539-1542, Dallas, Southern Methodist University Press.

Frago Gracia, Juan Antonio (1993): Historia de las hablas andaluzas, Madrid, Arco/Libros.

Galeote López, Manuel (1992): El léxico indioamericano de la flora y de la fauna en la obra historiográfica y científica de los cronistas andaluces de las Indias Occidentales, tesis doctoral, Granada, Universidad de Granada.

Galeote López, Manuel (2002): “Terminología botánica indígena en el vocabulario castellano-mexicano (1555) de Fray A. de Molina", Forma y Función, 15, pp. 102-118.

Girón Alconchel, José Luis (2004): "Cambios gramaticales en los Siglos de Oro", en Rafael Cano (coord.), Historia de la lengua española, Barcelona, Ariel, pp. 859-893.

Hammond, George P. y Agapito Rey (eds. y trads.) (1940): Narratives of the Coronado Expedition,1540-1542, 2, Albuquerque, University of New Mexico Press.

Hernández, Esther (1998): "La acomodación fonética de los nahuatlismos al español", Nueva Revista de Filología Hispánica, 46, 1, pp. 1-22, <https://doi.org/10.24201/nrfh.v46i1.2032>.

Hodge, Frederick W. (ed.) (1907): "The Narrative of the Expedition of Coronado, by Pedro de Castañeda", en Spanish Explorers in the Southern United States 1528-1543, New York, Scriber's, pp. 273-387.

Kania, Sonia (2013): “The Probanza de méritos of Vicente de Zaldívar (1602): Edition and Notes to Part 4", Romance Philology, 67, 2, pp. 261-316, <https://doi.org/10.1484/j.rph.5.103166>.

Kania, Sonia y Francisco Gago Jover (eds.) (2018-): Colonial Texts. Digital Library of Old Spanish Texts, Hispanic Seminary of Medieval Studies, <http://www.hispanicseminary.org/t\&c/col/ index-en.htm>.

Kania, Sonia, Cynthia Kauffeld y Israel Sanz-Sánchez (eds.) (2017): Relación de la jornada de Cíbola by Pedro de Castañeda de Nájera (1596), New York, Hispanic Seminary of Medieval Studies, CD-ROM.

Kessell, John L. (2002): Spain in the Southwest: A Narrative History of Colonial New Mexico, Arizona, Texas, and California, Norman, University of Oklahoma Press.

Lapesa, Rafael (1981): Historia de la lengua española, $9^{\text {a }}$ ed., Madrid, Gredos.

LHA = Harris-Northall, Ray y John J. Nitti (eds.). (2003-2007): Peter Boyd-Bowman's Léxico hispanoamericano 1493-1993, New York, Hispanic Seminary of Medieval Studies, [versión en línea] Ivy A. Corfis, Pablo Ancos, Fernando Tejedo y Philip Tibbetts (eds.), <textred.spanport. wisc.edu>.

Lloyd, Paul M. (1987): From Latin to Spanish, vol. 1: Historical Phonology and Morphology of the Spanish Language, Philadelphia, American Philosophical Society.

NDAI = Morínigo, Marcos A. (1998): Nuevo diccionario de americanismos e indigenismos, Buenos Aires, Claridad.

$N T L L E=$ Real Academia Española: Banco de datos [en línea]. Nuevo tesoro lexicográfico de la lengua española, <http://buscon.rae.es/ntlle/SrvltGUILoginNtlle>. 
Parodi, Claudia (2006): "The Indianization of Spaniards in New Spain", en Margarita Hidalgo (ed.), Mexican Indigenous Languages at the Dawn of the Twenty-First Century, Berlin, De Gruyter, pp. 29-53.

Parodi, Claudia (2009): "El español y las lenguas indígenas: primeros contactos", en Marta Islas (ed.), Entre las lenguas indígenas, la sociolingüística y el español: estudios en homenaje a Yolanda Lastra, München, Lincom Europa, pp. 478-511.

Penny, Ralph (2000): Variation and Change in Spanish, Cambridge, Cambridge University Press.

Penny, Ralph (2002): A History of the Spanish Language, $2^{\mathrm{a}}$ ed., Cambridge, Cambridge University Press.

Ramírez Luengo, José Luis (2017): "Aspectos metodológicos en el estudio histórico del léxico americano: conceptos, ejemplificación y tareas para el futuro", Moenia, 23, pp. 603-619.

Rosenblat, Ángel (1967): "Contactos interlingüísticos en el mundo hispánico: el español y las lenguas indígenas de América", en Jaime Sánchez Romeralo y Norbert Polussen (eds.), Actas del Segundo Congreso Internacional de Hispanistas, Nijmegen, Asociación Internacional de Hispanistas/Instituto Español de la Universidad de Nimega, pp. 109-154.

Santamaría, Francisco J. (1974): Diccionario de mejicanismos, $2^{\mathrm{a}}$ ed., México, Porrúa.

Smith, Andrew F. (ed.) (2013): The Oxford Encyclopedia of Food and Drink in America, 2a ed., Oxford, Oxford University Press, <https://www.oxfordreference.com/view/10.1093/ acref/9780199734962.001.0001/acref-9780199734962>

Torrens Álvarez, María Jesús (2007): Evolución e historia de la lengua española, Madrid, Arco/ Libros.

Torres Torres, Antonio (2004): Procesos de americanización del léxico hispánico, Valencia, Universitat de València.

Weber, David J. (1992): The Spanish Frontier in North America, New Haven, Yale University Press.

Winship, George P. (ed. y trad.) (1896): The Coronado Expedition, 1540-1542, Bureau of Ethnology, Smithsonian Institution, Annual Report, 14, Washington, D.C., Government Printing Office.

Fecha de recepción: 6 de enero de 2020

Fecha de aceptación: 6 de marzo de 2020 
